\title{
Cancer incidence in Priolo, Sicily: a spatial approach for estimation of industrial air pollution impact
}

\author{
Lucia Fazzo, ${ }^{1}$ Mario Carere, ${ }^{1}$ Francesco Tisano, ${ }^{2}$ Caterina Bruno, ${ }^{1}$ Achille Cernigliaro, ${ }^{3}$ \\ Maria Rita Cicero, ${ }^{1}$ Pietro Comba, ${ }^{1}$ Maria Luisa Contrino, ${ }^{2}$ Marco De Santis, ${ }^{1}$ \\ Fabrizio Falleni, ${ }^{1}$ Vincenzo Ingallinella, ${ }^{4}$ Anselmo Madeddu, ${ }^{2}$ Ida Marcello, ${ }^{5}$ \\ Carlo Regalbuto, ${ }^{6}$ Giovanna Sciacca, ${ }^{2}$ Maria Eleonora Soggiu, ${ }^{1}$ Amerigo Zona ${ }^{1}$ \\ ${ }^{1}$ Department of Environment and Primary Prevention, National Institute of Health, Rome; \\ ${ }^{2}$ Cancer Registry of Syracuse Province, Health Unit of Syracuse Province, Syracuse; \\ ${ }^{3}$ Department of Health Services and Epidemiological Observatory, Regional Health \\ Authority, Sicilian Region, Palermo; ${ }^{4}$ Health Unit of Syracuse Province, Augusta; \\ ${ }^{5}$ National Centre for Chemical Substances, National Institute of Health, Rome; \\ ${ }^{6}$ Regional Environmental Protection Agency, Sicilian Region, Palermo, Italy
}

\begin{abstract}
The territory around the industrial Sicilian area of Priolo, Italy, has been defined as a contaminated site (CS) of national priority for remediation because of diffuse environmental contamination caused by large industrial settlements. The present study investigates the spatial distribution of cancer into the CS territory (period 1999-2006). Different geographical methods used for the evaluation of the impact of industrial air pollutants were adopted. Using the database of Syracuse Province Cancer Registry, gender-specific standardised incidence ratios were calculated for 35 tumour sites for the CS overall and for each municipality included in the CS. A cluster analysis for 17 selected neoplasms was performed at micro-geographical level. The identification of the priority index contaminants (PICs) present in environmental matrices and a review of their carcinogenicity have been performed and applied in the interpretation of the findings. The area has a higher cancer incidence with respect to the provincial pop-
\end{abstract}

Correspondence: Lucia Fazzo, Department of Environment and Primary Prevention, National Institute of Health, viale Regina Elena 299, 00161 Rome, Italy.

Tel: +39.06 .4992537 - Fax: +39.06 .49387084 .

E-mail: lucia.fazzo@iss.it

Key words: Contaminated site; Cancer incidence; Petrochemical; Geographical analysis; Sicily.

Received for publication: 14 January 2015.

Revision received: 20 0ctober 2015.

Accepted for publication: 20 October 2015.

(C) Copyright L. Fazzo et al., 2016

Licensee PAGEPress, Italy

Geospatial Health 2016; 11:320

doi:10.4081/gh.2016.320

This article is distributed under the terms of the Creative Commons Attribution Noncommercial License (CC BY-NC 4.0) which permits any noncommercial use, distribution, and reproduction in any medium, provided the original author(s) and source are credited. ulation, in particular excess is registered among both genders of lung, bladder and breast cancers as well as skin melanoma and pleural mesothelioma and there is an a priori evidence of association with the exposure to PICs. The study highlights the need to provide different approaches in CSs where several exposure pathways might be relevant for the population. The presence of potential sources of asbestos exposure deserves specific concern.

\section{Introduction}

The European Environmental Agency (EEA) estimates 342,000 contaminated sites (CSs) in the 33 members and six cooperating countries, on the basis of the soil contamination regulation; one third of them has already been identified and about $15 \%$ have been remediated (van Liedekerke et al., 2014). In Europe, the World Health Organization (WHO) has recently developed a comprehensive approach aimed at assessing the health status of populations resident in contaminated sites (WHO, 2013), including recommendations for epidemiological surveillance programmes.

In Italy, the criteria for definition of CSs of national concern for remediation to be included in the National Priority List, were firstly defined in 1998 and subsequently updated in 2006. Currently, 39 Italian national priority list CSs (NPCSs) have been defined and included in the national remediation programme. Among them, the CS of Priolo in Sicily was already identified in 1998 and confirmed in the most recent national framework decree (152/2006). The site of Priolo is characterised by a diffuse environmental contamination due to the presence of large industrial settlements that in the last decades has caused a progressive contamination of the different environmental compartments. Toxic, persistent and bio-accumulable compounds, such as heavy metals, polychlorinated biphenyls (PCBs), dioxins and polycyclic aromatic hydrocarbons (PAHs) were detected and the past and present exposure to Volatile organic compounds (VOCs) was ascertained (Beccaloni et al., 2014).

The overall area included in the Priolo CS was considered in the national programme of epidemiological surveillance in contaminated sites, the SENTIERI Project (Pirastu et al., 2013, 2014). The incidence of all cancers in the population living in the Priolo CS showed an excess in both genders with respect to the pool of cancer registries of 
central and southern Italy; specific neoplasms in excess included tumours of the liver and pancreas and mesothelioma. In the analysis by gender, an excess of tumours of the lung, bladder and central nervous system were detected in men and so was the case for colon-rectum, breast and uterus in women (Pirastu et al., 2014). Increases of mortality and hospitalisation for specific neoplasms were found in the population living in the Priolo CS also with respect to the neighbouring municipalities and the Sicilian regional rates (Dipartimento Attività Sanitarie ed Osservatorio Epidemiologico. Assessorato Regionale della Salute, 2012). The present study investigates the incidence of tumours with respect to the Province of Syracuse, Sicily. These populations are more similar, in terms of access to healthcare, quality of diagnosis, lifestyle, etc., than that used in previous studies. We emphasise the types of cancer with a possible positive association with the contaminants, defined as priority index contaminants (PICs), detected in the area considering the following criteria: quality of information, presence in different environmental matrices, levels of detected concentrations, diffusion of the contamination(s) in the areas with risk for population exposure. Furthermore, the distribution of cancer cases in the CS territory under study was examined taking into account the impact area of atmospheric pollutants emitted by the plants and taking into account that environmental pressure due to the concurrent presence of multiple carcinogenic agents may affect the resident population through different routes of exposure and pathogenic mechanisms. The present study is mainly focused on inhalation exposure to carcinogenic pollutants emitted by industrial sources that can be the object of a spatial analysis as well as testing the hypothesis of clustering.

\section{Materials and Methods}

The study area extends for about $14 \mathrm{~km}$ along the Sicilian southeastern coast including two refineries, three petrochemical plants, a liquid gas production plant, an incinerator of harbour waste, a cement plant, a former asbestos-cement plant (Eternit) and several landfills comprising hazardous waste. Priolo CS, including the municipalities of Augusta, Priolo, Melilli and Syracuse, covers a total area of $159 \mathrm{~km}^{2}$ (about 58 of land and 100 of sea) and comprises the harbour areas of Syracuse and Augusta Bay (Figure 1).

\section{Environmental contamination}

In order to identify the main contaminants present in the area, environmental data made available by the Sicilian Region Environmental Protection Agency (ARPA) were considered. Since the present study is based on the residence of cancer patients, special attention was given to the spatial patterns of air pollution for which several data sources were considered: air quality monitoring network, atmospheric emissions from the industries and bio-monitoring of lichens for metal inclusions. An atmospheric dispersion model (ISCST3) (Lakes Environmental, 2013) was applied to industrial emissions, taking into account the meteorological data and terrain heights of the area, in order to obtain concentration maps of sulfur dioxide $\left(\mathrm{SO}_{2}\right)$, nitrogen oxides (NOx) and particulate matter (PM) emitted by industrial point sources, and to investigate their impact on air quality. About 100 point sources were identified and emission data of specific contaminants were acquired. The atmospheric dispersion was simulated on a grid of $111 \times 150$ regular receptors, over an area of $22 \mathrm{~km}$ x $39 \mathrm{~km}$, and on seven discrete receptors corresponding to the position of the monitoring stations. The simulated concentrations of $\mathrm{SO}_{2}$ were compared with the $\mathrm{SO}_{2}$ concentrations measured by the air quality-monitoring network (period 2008-2012), with the aim of verifying the reliability of the dispersion model. The annual investigations (2006 and 2007) of the lichen bio-monitoring analysed the following heavy metals in samples from 36 stations: arsenic, cadmium, chromium, mercury, nickel, vanadium and lead (ARPA Sicilia, 2008). The annual averages of the contaminants were subject of a statistical analysis and an ordinary Kriging method. The latter is a geostatistical estimator that infers the value of a random field at an unobserved location from samples producing a prediction surface that provides measures of the certainty or accuracy of the predictions (Johnston et al., 2001; Cressie, 2002). The model involved data pre-processing to remove spatial trends and data transforming in a Gaussian distribution, whose application was feasible only for vanadium and nickel.

\section{Evaluation of priority index contaminants carcinogenicity}

Based on a review of the environmental contamination data made available by the ARPA, a list of PICs was identified, on the basis of the criteria described above. The epidemiological evidence of the carcinogenicity of identified PICs was evaluated following the procedure described by Zona et al. (2014), which considers information about the carcinogenicity of pollutants elaborated by several scientific institutions (such as the International Agency for Research on Cancer, the Agency for Toxic Substances and Disease Registry, the US Environmental Protection Agency, the European Food Safety Authority). The tumour sites were grouped on the basis of the strength of the association with exposure to the PICs investigated: group a) sufficient evidence; group b) - limited evidence; group c) - positive

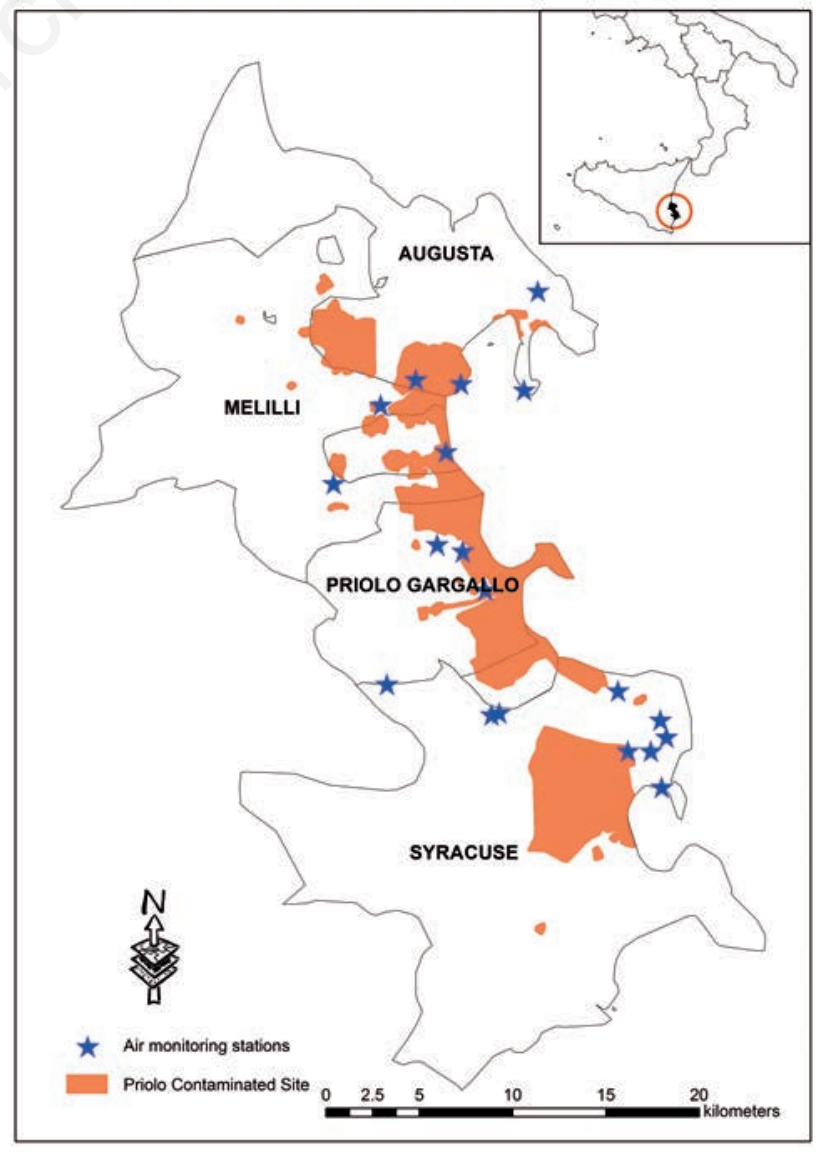

Figure 1. National priority contaminated site of Priolo, Sicily. 
association (i.e., the neoplasms for which the strength of evidence was not available but where a positive association was reported).

\section{Cancer incidence data and epidemiological analysis}

The present study was based on data of the Cancer Registry of Syracuse Province that includes the four municipalities constituting Priolo CS. The Registry is part of the Italian Network of Cancer Registries (AIRTum) and is certified by the International Agency for Research on Cancer (IARC) (Curado et al., 2007; Madeddu et al., 2009). The Registry certifies all cases living in Syracuse Province at the time of diagnosis (period 1999-2006 - at the start of the present investigation). To obtain information on the burden of cancer diseases in the population, 35 neoplasms (or groups of neoplasms) classified on the basis of topographic criteria [International Classification Diseases for Oncology $3^{\text {rd }}$ edition (ICD-0-3) codes], were considered. Subjects resident in the investigated municipalities and diagnosed with one of the selected neoplasms in the time-window of the study identified in Cancer Registry database and their addresses at the time of diagnosis were obtained from Municipal Registrar Offices.

Standardised incidence ratios (SIRs), and their corresponding 95\% Confidence Intervals for each selected cancer site, were computed for the Priolo CS overall area and for each municipality included in the CS with respect to Syracuse Province. The provincial reference rates were calculated on the basis of the cancer cases diagnosed in the period 1999-2006 and the population living at 1/1/2003 multiplied by the eight-year period of observation; the residents in the study area were excluded. The analyses, standardised by age-classes, were performed separately by gender, using the STATA statistical software (StataCorp, 2010). Subsequently, cluster analysis was performed to investigate the spatial aggregation of the cases into the study area aiming at the census-tracts, the smallest administrative units for which resident population data are available. The analysis was carried out for those neoplasms, for which an etiological role of environmental exposures was hypothesised on the basis of scientific evidence available at the time of study design: cancer of the liver, pancreas, larynx, lung, testis, bladder, thyroid, pleural mesothelioma, melanoma of skin and lymphoematopoietic system neoplasms, nonHodgkin lymphomas, Hodgkin's disease, leukaemias (lymphoid leukaemias, acute and chronic; myeloid leukaemias, acute and chronic). Clustering was tested both including and excluding Syracuse Municipality, the most populated town in the study area; the analysis of liver cancer was, however, carried out excluding Syracuse because of the unavailability of residence information for the cases living in this municipality. The address of each case at time of diagnosis was mapped in a geographical information systems (GIS) software including the geographic boundaries of census-tracts and each case was attributed to the corresponding census-tract. The population residing in each censustract was computed on the basis of 2001 Census population data, multiplied by eight, the years of the observation period. Spatial clusters of cases were identified by using SatScan software, version 6 (Kuldorff, 1997) assuming a Poisson model for the distribution of cases in each census-tract. The adopted spatial scan statistics procedure employs a circular window whose radius was fixed with a maximum of $3 \mathrm{~km}$ centred at each step on one census-tract, identified by the $\mathrm{x}, \mathrm{y}$ coordinates of its geographic centroid. Significant levels were fixed at $\mathrm{P}<0.1$.

\section{Results}

The review of the environmental data showed a diffuse, widespread chemical contamination in all environmental compartments with high concentrations of hazardous substances in soil, groundwater and fisheries in the whole Priolo CS area. However, there was no available information on some highly toxic micropollutants (i.e. polycyclic aromatic hydrocarbons, dioxin, metals) in the atmospheric particulate matter.

\section{Environmental contamination}

The analysis of air quality monitoring data shows that hourly $\mathrm{SO}_{2}$ concentrations are well associated with industrial emissions detecting higher concentrations in concordance with the wind directions blowing from industrial sources. For NOx and $\mathrm{PM}_{10}$ (particulates matter with aerodynamic diameter $\leq 10$ micrometers) the contribution from other sources (typically traffic emissions) produces a background value, which does not allow to point out correlations with industrial emissions; only in two monitoring stations higher concentrations of $\mathrm{NO}_{2}$, NOx and benzene suggest an association with the wind blowing from plants. The comparison of the simulated and observed $\mathrm{SO}_{2}$ concentrations showed a good agreement. Figure 2 shows the impact area of air dispersion model of $\mathrm{SO}_{2}$ industrial emissions.

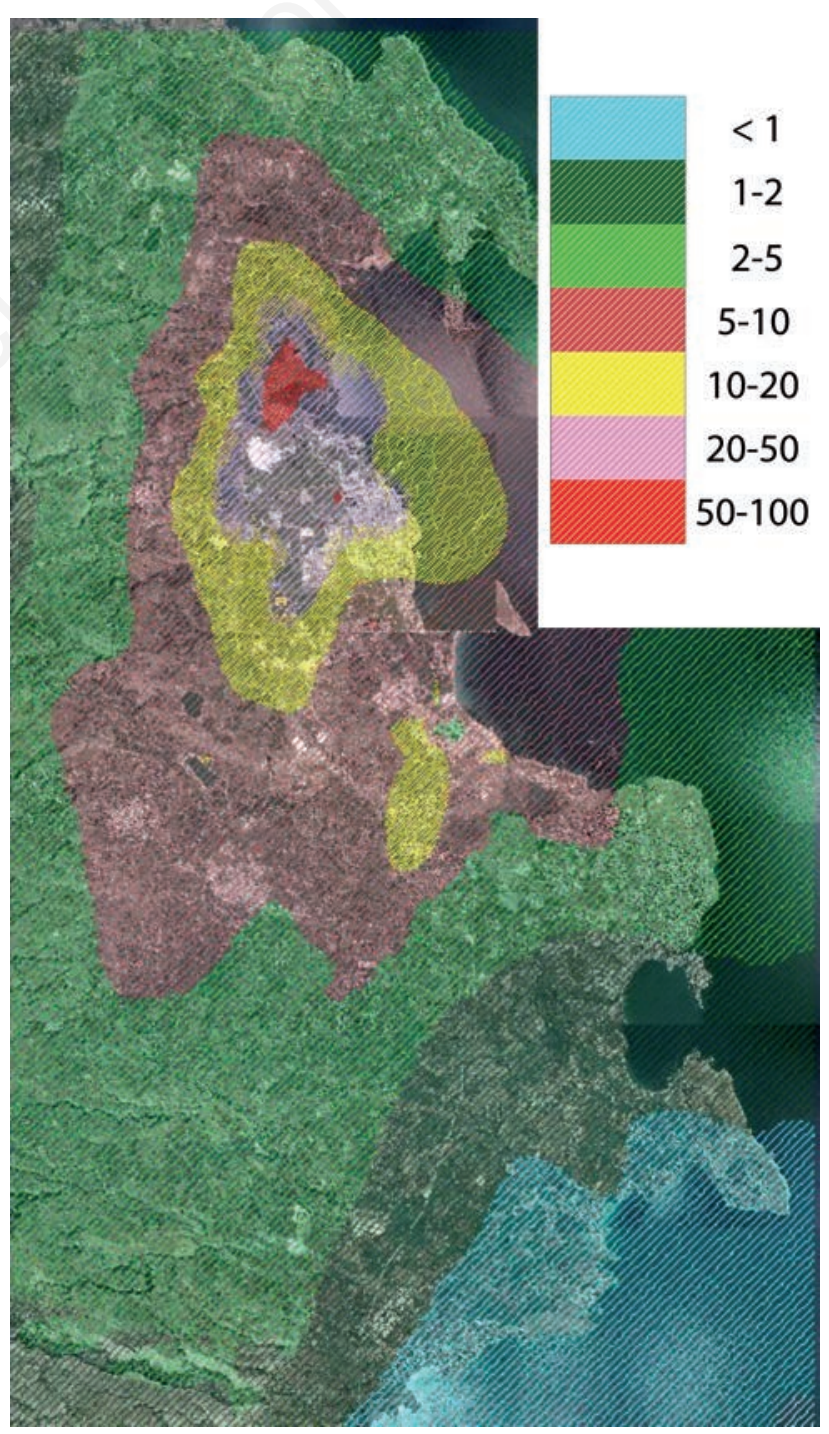

Figure 2. Air dispersion model of $\mathrm{SO}_{2}$ industrial emissions $\left(\mu \mathrm{g} / \mathrm{m}^{3}\right)$. 
The study on metal inclusion in lichens highlighted a contamination of industrial origin for zinc, copper, mercury, cadmium and chromium. The statistical analysis showed a specificity of metal accumulation in different stations, generating the hypothesis of different sources of pollution. The stations, which presented the highest values for several of these contaminants, are located in the southern area of Augusta and the western area of Melilli. Figure 3 shows the results of the Kriging model for vanadium and nickel lichen bio-monitoring, the agents for which the model was fitted. The distribution of the two contaminants is similar, with the highest values concentrated in the industrial area [maximum: $7.9 \mathrm{mg} / \mathrm{kg}$ dry weight (dw), vanadium; $9 \mathrm{mg} / \mathrm{kg} \mathrm{dw}$, nickel] and a distribution in accordance with the prevailing wind directions. In summary, the southern area of Augusta municipality, downwind of industrial emissions, and the part of Priolo municipality nearest to the industrial area, appear to be mainly affected by atmospheric dispersion of the industrial emissions.

Contamination of soil, groundwater and sediments was also considered in order to estimate the whole environmental burden present in the area. Indeed, chemical contamination of all environmental compartments was evident with concentrations of various hazardous substances present at several orders of magnitude above the threshold values allowed by environmental and health regulations. Because of the massive contamination of soil, groundwater and sediments, the risk of exposure to hazardous substances through different pathways, other than inhalation, such as drinking water, ingestion of local agricultural products including fisheries, was also hypothesised. On this ground, a number of PICs, as defined in the methodology section, were evaluated (Table 1).

\section{Evaluation of contaminant carcinogenicity}

Table 2 shows the cancer sites or tissues with a positive association with one, or more PIC(s) on the basis of the evaluation of international scientific institutions documents (ECHA, 2013; IARC, 1993, 1997, 1999,
2001, 2006a, 2006b, 2012a, 2012b, 2014b; NTP 2014; USEPA, 1991, 1998, 2010,2011,2013); as previously stated, neoplasms or tumour sites were grouped on the basis of strength of association.

Group a) (sufficient evidence): all malignant neoplasms, stomach, liver, lung, cutaneous melanoma, kidney, urinary bladder and acute myeloid leukaemia/acute non-lymphocytic leukaemia.

Group b) (limited evidence): malignant neoplasms of biliary tract, breast, prostate, soft tissue sarcomas and non-Hodgkin lymphomas.

Group c) (positive association): multiple myeloma, acute and chronic lymphocytic leukaemias.

\section{Cancer incidence data and epidemiological analyses}

The epidemiological investigation considered 2552 cases (1808 men and 744 women) living in the Priolo CS area at the time of diagnosis, which had a diagnosis of neoplasm in one of the 34 selected cancer sites in the 1999-2006 period. In the same period, 15,789 total cancer cases (9097 males and 6692 females) were diagnosed in the province of Syracuse. The population served by the Cancer Registry of Syracuse Province constituted 396,517 inhabitants (194,104 men and 202,413 women) at $1 / 1 / 2003$. The cases under study are distributed in the four municipalities as follows: 549 in Augusta (376 men and 173 women), 131 in Melilli (95 men and 36 women), 138 in Priolo (101 men and 37 women) and 1734 in Syracuse (1236 men and 498 women). Tables 3 and 4 show the SIRs in the overall CS area and in each municipality, respectively. Among malignancies with a sufficient $a$ priori evidence of association with contaminants (group a), all malignant neoplasms, lung and urinary bladder cancers and cutaneous melanoma were in excess of expected numbers in both genders in the CS overall area. At the municipal level, an increased incidence of all malignant neoplasms in both genders was observed in Syracuse and in Augusta, whereas this finding was only found to be present in the male population in Priolo. The increase of lung cancer was also evident in both genders in Syracuse municipality and in the male population of Augusta.

Table 1. Priority index contaminants in the area of the Priolo contaminated site.

\begin{tabular}{|c|c|c|c|c|c|c|}
\hline 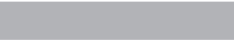 & Industrial soil & Groundwater & Pine trees needles ${ }^{\circ}$ & Lichens $^{\circ}$ & Sediment\# & Fish products \\
\hline Arsenic & $\mathrm{X}$ & $\mathrm{X}$ & $\mathrm{X}$ & $\mathrm{X}$ & $\mathrm{X}$ & \\
\hline Cadmium & $\mathrm{X}$ & & & $X$ & & $\mathrm{X}$ \\
\hline Chromium total & $\mathrm{X}$ & $\mathrm{X}$ & $\mathrm{X}$ & $\mathrm{X}$ & $\mathrm{X}$ & \\
\hline Chromium VI & $\mathrm{X}$ & $\mathrm{X}$ & & & & \\
\hline Mercury & $\mathrm{X}$ & $\mathrm{X}$ & & $\mathrm{X}$ & $\mathrm{X}$ & $\mathrm{X}$ \\
\hline Lead & $\mathrm{X}$ & $\mathrm{X}$ & $\mathrm{X}$ & $\mathrm{X}$ & $\mathrm{X}$ & $\mathrm{X}$ \\
\hline Nickel & & $\mathrm{X}$ & $\mathrm{X}$ & $\mathrm{X}$ & & \\
\hline Vanadium & $\mathrm{X}$ & $\mathrm{X}$ & $\mathrm{X}$ & $\mathrm{X}$ & $\mathrm{X}$ & \\
\hline 1,2Dichloroethane & $\mathrm{X}$ & $\mathrm{X}$ & & & & \\
\hline Benzene & $\mathrm{X}$ & $\mathrm{X}$ & & & & \\
\hline Vinyl Chloride & $\mathrm{x}$ & $\mathrm{X}$ & & & & \\
\hline Hexachlorobenzene & $\mathrm{X}$ & $\mathrm{X}$ & & & $\mathrm{X}$ & $\mathrm{X}$ \\
\hline Tetrachloroethylene & $\mathrm{x}$ & $\mathrm{X}$ & & & & \\
\hline Xylene & $\mathrm{X}$ & $\mathrm{X}$ & & & & \\
\hline Trichloroethylene & & $\mathrm{X}$ & & & & \\
\hline Hydrocarbons $\mathrm{C}<12$ & $\mathrm{X}$ & & & & & \\
\hline Hydrocarbons C>12 & $\mathrm{X}$ & & & & & \\
\hline Hydrocarbons total & & $\mathrm{X}$ & & & & \\
\hline
\end{tabular}


Cutaneous melanoma incidence was in excess in both genders in Syracuse and among women in Augusta. Urinary bladder tumours were found in excess in Syracuse in both genders. Malignant liver neoplasms were in excess among females in the CS overall area and in Augusta, kidney tumours in males (CS overall area) and females (Syracuse). Stomach cancer showed a decrease with respect to the reference population among men in Syracuse. However, the incidence of acute myeloid leukaemia/acute non-lymphocytic leukaemia did not depart from the expected, neither in the whole CS nor in each municipality. Regarding incidence of malignant tumours with a limited $a$ priori evidence of association with contaminants (group b), increased numbers were observed for breast cancer in both genders in the CS overall area, in Syracuse and in females in Augusta. Prostatic cancer was in excess in CS overall area and in Syracuse and Priolo municipalities. Increases in Syracuse male population were found for nonHodgkin lymphomas and chronic lymphocytic leukaemia; the latter increased also among men in the CS overall area.

The increases of pleural mesothelioma observed in both genders in the CS overall area as well as all municipalities, except Melilli, deserve particular mention due to the occupational exposure to asbestos, which was documented both in Syracuse (former asbestos-cement plant) and in Augusta (refineries, chemical industries, shipbuilding and repair industries).

The cluster analysis showed significant results mainly in Syracuse, the most populated town of the study area, except a cluster of pancreas tumour found among women in Augusta municipality. In the analysis without Syracuse, significant clusters were located in one sub-area of Augusta, which is affected by atmospheric industrial emissions. Out of the cancer types of group a) (with a sufficient a priori evidence of association with PICs present in the CS), lung cancer [neoplasm also in group c), because of the association with benzo(a)pyrene] constituted significant clusters in both genders in Syracuse and among women in Augusta (the latter in the analysis without Syracuse municipality) (Figure 4). Non-Hodgkin lymphomas, with a limited a priori evidence of association with dioxins, PCBs and trichloro-ethylene (group b) and a positive association with benzene and tetrachloroethylene (group c), appeared as a significant cluster among men in Syracuse; only one cluster was found in Priolo census-tracts that consisted of lymphocytic chronic leukaemia (diseases for which an association with present contaminants was reported, group c) among men (Figure 5). Pancreatic and thyroid cancers presented significant clusters (Figure 6 ), but the a priori evaluation did not offer clues for an association with PICs detected in study area. In summary, most examples of increased cancer incidence were found to be located in the municipalities of Syracuse and Augusta with only specific neoplasms (lung in both genders, Hodgkin and non-Hodgkin lymphomas in only men, and myeloblastic, chronic leukaemias in only women) grouped in specific subareas of Syracuse municipality.
A
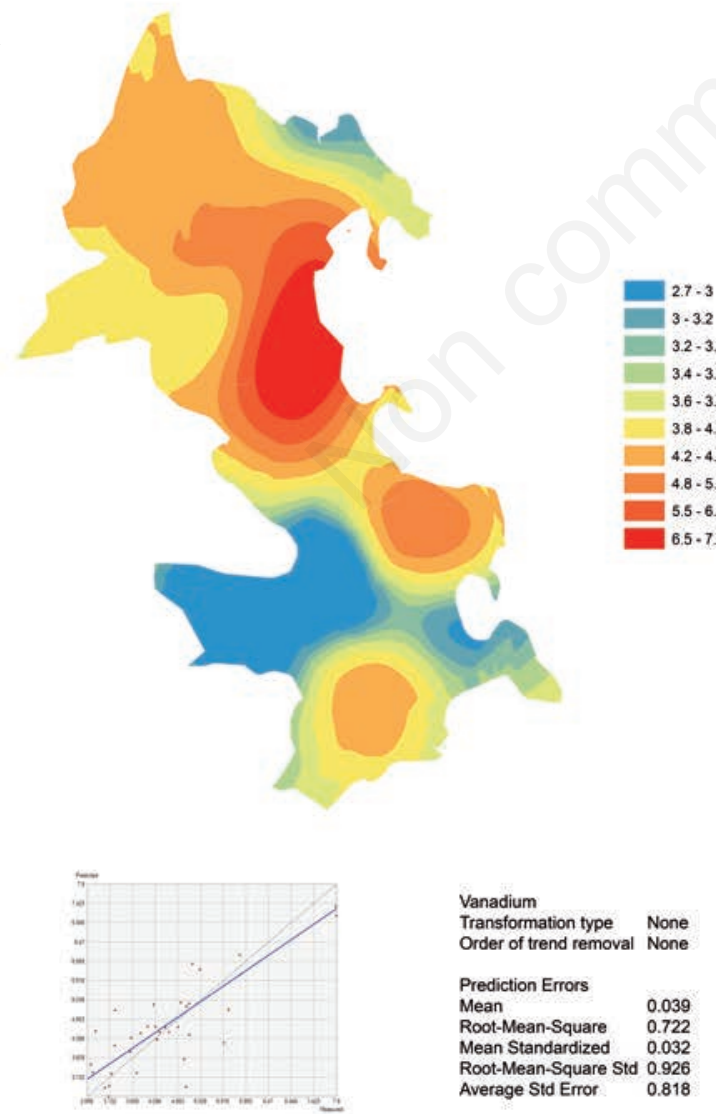

Vanadium Order of trend removal None Prediction Errors Mean Root-Mean 0.039 Mean Standardized $\quad 0.032$ Root-Mean-Square Sid 0.926
Transformation type None

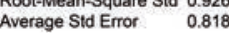

B
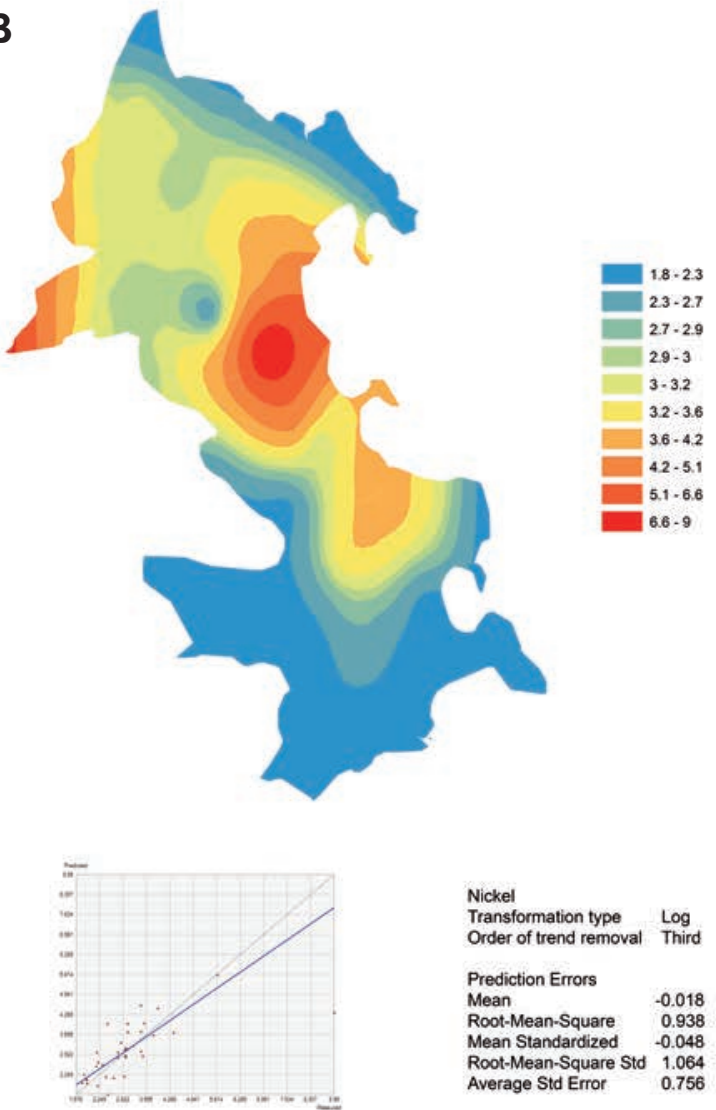

Nickel

Transformation type Log Order of trend removal Third Prediction Errors Mean $\quad-0.018$ Root-Mean-Square $\quad 0.938$ Mean Standardized $\quad-0.048$ Root-Mean-Square Std 1.064

Figure 3. Kriging model maps of vanadium (A) and nickel (B). 


\section{Discussion}

In light of the characteristics of the present investigation being based on a geographical study design, the air contamination was primarily taken into account to evaluate the impact of sub-areas as the study of wind directions and pollution is straightforward. However, there are reasons to believe that other routes of exposure, such as drinking water and ingestion of fish and food, might be just as relevant. The population has probably been exposed to a mixture of pollutants by different routes and appropriate exposure modelling and risk-assessment procedures should be implemented in order to assess their relative contribution.

A limitation of the present study is that it mainly focused on inhalation exposure to carcinogenic pollutants emitted by industrial sources that can be the object of a spatial analysis as well as testing the hypothesis of clustering. Other exposure pathways (e.g. diet, occupation) could not be appropriately dealt with by the spatial approaches adopted in the present investigation, but may nevertheless have significantly contributed to the overall burden of cancer. With regard to the epidemi- ological results, it should be considered that all the selected neoplasms have a multifactorial etiology, which is not always completely known. The study design did not permit to have information about individual occupational and environmental exposures patterns, lifestyle and socioeconomic conditions. For these main reasons, the role of factors other than environmental chemical exposure cannot be ruled out.

The different approaches used for investigate the spatial variability of concentrations of atmospheric industrial pollutants are mutually consistent. The value of Kriging in supporting the inhalation exposure assessment in industrial areas has recently been discussed (VicedoCabrera et al., 2013). The results, showing the highest values around polluting industries are in agreement with prevailing wind directions and confirm that the air quality of the CS areas is affected by industrial atmospheric emissions. In particular, specific sub-areas, in south-western part of Augusta and in part of Priolo municipality seem to be particularly affected by the impact of air pollutants emitted by industries.

The reported increased cancer numbers require a preliminary consideration. The process of environmental characterisation of this area has generated a set of cancer sites, for which a priori hypotheses of etiological interest based on sufficient or limited evidence of association
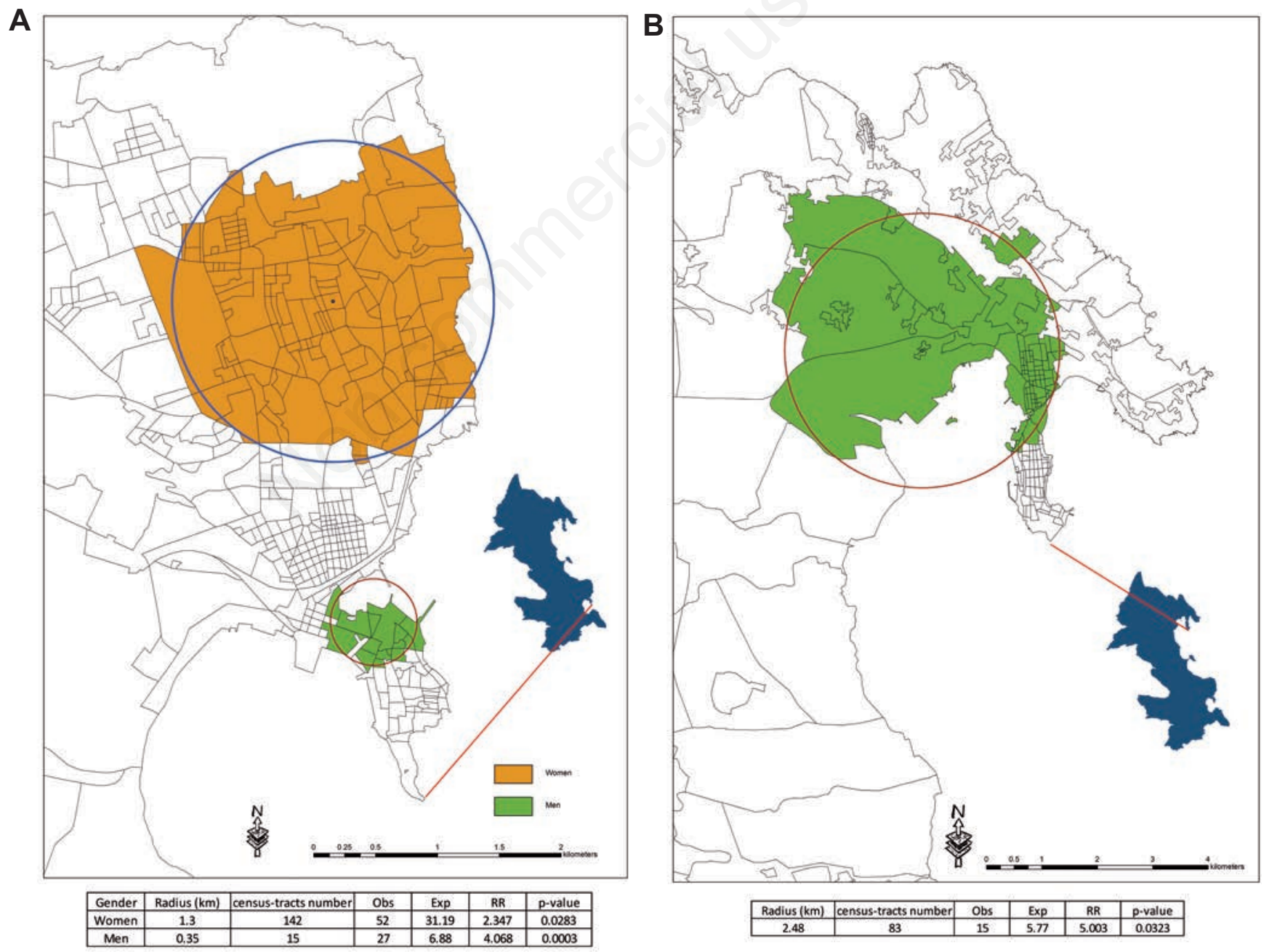

Figure 4. Significant clusters of lung cancer in women and men including Syracuse (A), and in women excluding Syracuse (B). 
with specific contaminants (PICs) detected in the area are available. The observation of excess incidence in these cancer sites must be regarded as being most informative in terms of causal reasoning. The observed increases in the number of cancer are consistent with previous epidemiological studies on the population living in the Priolo CS. In the present study the increased cancer occurrences were detected in relation to the provincial population, and that is more similar to the population at study than the reference used in previous studies, such as those of the pool of Cancer Registries of Central and Southern Italy (Pirastu et al., 2014). In particular, lung cancer is associated with sufficient evidence to exposure to specific metals (arsenic, cadmium, hexavalent chromium and nickel compounds) (IARC, 2014a), with limited evidence to 2,3,7,8-tetrachlorodibenzodioxin (2,3,7,8-TCDD)
(IARC, 2014b) and an association with benzo(a)pyrene has been reported (USEPA, 2013). Cutaneous melanoma is associated with sufficient evidence to PCBs exposure (IARC, 2014c). Urinary bladder cancer is associated with sufficient evidence arsenic exposure and with limited evidence to tetrachloroethylene and an association has been reported with benzo(a)pyrene (IARC, 2014a, 2014b; USEPA, 2013). Limited evidence has been reported for the association between prostatic cancer and exposure to arsenic and cadmium (IARC, 2014a); for chronic lymphocytic leukaemia an association has been reported with exposure to benzene (IARC, 2012b). The increased occurrence of breast cancer found in both genders have to be highlighted. Male breast cancer is a rare disease and the increase found in the present investigation, based on 13 cases, deserves particular attention: in fact,

Table 3. Standardised incidence ratios in Priolo contaminated site, overall area (1999-2006).

\begin{tabular}{|c|c|c|c|c|c|c|c|}
\hline Type of malignant neoplasm & ICD-0-3 code & & Men & & & Nome & \\
\hline & & Obs & SIR & $95 \% \mathrm{CI}$ & Obs* & SIR & $95 \% \mathrm{CI}$ \\
\hline All malignant neoplasms & $\mathrm{C} 00-\mathrm{C} 043, \mathrm{C} 45-\mathrm{C} 96, \mathrm{D} 090$ & 3426 & 1.20 & $1.16-1.24$ & 2732 & 1.14 & $1.10-1.18$ \\
\hline Oesophagus & $\mathrm{C} 15$ & 16 & 0.85 & $0.48-1.37$ & 5 & 0.68 & $0.22-1.58$ \\
\hline Stomach & $\mathrm{C} 16$ & 108 & 0.83 & $0.68-1.00$ & 59 & 0.89 & $0.67-1.14$ \\
\hline Colon-rectum & $\mathrm{C} 18-21$ & 422 & 1.18 & $1.07-1.30$ & 360 & 1.05 & $0.94-1.16$ \\
\hline Liver & $\mathrm{C} 22$ & 167 & 1.10 & $0.94-1.28$ & 95 & 1.35 & $1.10-1.65$ \\
\hline Gallbladder and biliary tract & $\mathrm{C} 23-24$ & 46 & 1.18 & $0.86-1.57$ & 69 & 1.20 & $0.93-1.52$ \\
\hline Pancreas & $\mathrm{C} 25$ & 108 & 1.35 & $1.10-1.62$ & 107 & 1.46 & $1.19-1.76$ \\
\hline Larynx & C32 & 91 & 1.48 & $1.19-1.82$ & 1 & 0.14 & $0.00-0.76$ \\
\hline Trachea, bronchus and lung & C33-34 & 609 & 1.23 & $1.13-1.33$ & 109 & 1.23 & $1.01-1.48$ \\
\hline Mesothelioma of pleura & C45 & 38 & 2.23 & $1.58-3.06$ & 9 & 2.21 & $1.01-4.19$ \\
\hline Connective and soft tissue & C49 & 18 & 0.77 & $0.46-1.21$ & 13 & 0.72 & $0.38-1.22$ \\
\hline Melanoma of skin & $\mathrm{C} 43$ & 64 & 1.39 & $1.07-1.78$ & 66 & 1.96 & $1.51-2.49$ \\
\hline Bone & $\mathrm{C} 40-\mathrm{C} 41$ & 9 & 0.91 & $0.42-1.73$ & 6 & 1.40 & $0.51-3.05$ \\
\hline Breast & C50 & 13 & 2.00 & $1.06-3.42$ & 814 & 1.15 & $1.07-1.23$ \\
\hline Uterus & C53-C54 & & & & 216 & 0.89 & $0.78-1.02$ \\
\hline Cervix of uterus & C53 & & & & 51 & 0.77 & $0.58-1.02$ \\
\hline Corpus of uterus & $\mathrm{C} 54$ & & & & 165 & 0.94 & $0.80-1.09$ \\
\hline Ovary & $\mathrm{C} 56$ & & & & 97 & 1.05 & $0.85-1.28$ \\
\hline Prostate & $\mathrm{C} 61$ & 494 & 1.22 & $1.12-1.34$ & & & \\
\hline Testis & C62 & 44 & 1.40 & $1.02-1.89$ & & & \\
\hline Bladder & C67, D090 & 490 & 1.19 & $1.08-1.30$ & 84 & 1.57 & $1.25-1.94$ \\
\hline Kidney and other urinary organs & C64-C66, C68 & 87 & 1.30 & $1.04-1.60$ & 39 & 1.31 & $0.93-1.79$ \\
\hline Central nervous system & C70-C72 & 79 & 1.52 & $1.20-1.89$ & 47 & 1.02 & $0.75-1.36$ \\
\hline Thyroid gland & $\mathrm{C} 73$ & 39 & 1.28 & $0.91-1.75$ & 151 & 1.17 & $0.99-1.37$ \\
\hline Lymphohemopoietic system & C81-C96 & 301 & 1.15 & $1.02-1.28$ & 213 & 1.08 & $0.94-1.24$ \\
\hline Non-Hodgkin lymphomas & $\mathrm{C} 82-85, \mathrm{C} 96$ & 114 & 1.10 & $0.90-1.32$ & 87 & 1.04 & $0.83-1.28$ \\
\hline Hodgkin lymphoma & $\mathrm{C} 81$ & 26 & 1.36 & $0.89-1.99$ & 23 & 1.37 & $0.87-2.05$ \\
\hline Myeloma & $\mathrm{C} 88, \mathrm{C} 90$ & 55 & 1.12 & $0.84-1.45$ & 44 & 1.24 & $0.90-1.66$ \\
\hline Leukaemias & C91-C95 & 106 & 1.17 & $0.96-1.42$ & 59 & 0.98 & $0.74-1.26$ \\
\hline Lymphoid leukaemias & С910-С911 & 48 & 1.50 & $1.10-1.98$ & 24 & 0.95 & $0.61-1.42$ \\
\hline Acute lymphoblastic leukaemia & C910 & 13 & 0.93 & $0.49-1.58$ & 10 & 1.17 & $0.56-2.16$ \\
\hline Chronic lymphocitic leukaemia & C911 & 35 & 1.94 & $1.35-2.70$ & 14 & 0.84 & $0.46-1.41$ \\
\hline Myeloid leukaemias & С920-C921 & 43 & 1.12 & $0.81-1.51$ & 24 & 1.15 & $0.74-1.71$ \\
\hline Acute myeloblastic leukaemia & C920 & 24 & 1.02 & $0.65-1.51$ & 14 & 1.03 & $0.56-1.72$ \\
\hline Chronic myeloid leukaemia & C921 & 19 & 1.30 & $0.78-2.02$ & 10 & 1.40 & $0.67-2.57$ \\
\hline
\end{tabular}

ICD-0-3, International Classification Diseases for Oncology, 3rd edition; Obs, observed cases; SIR, standardised incidence ratio; 95\%CI, 95\% confidence interval. 


\section{Article}

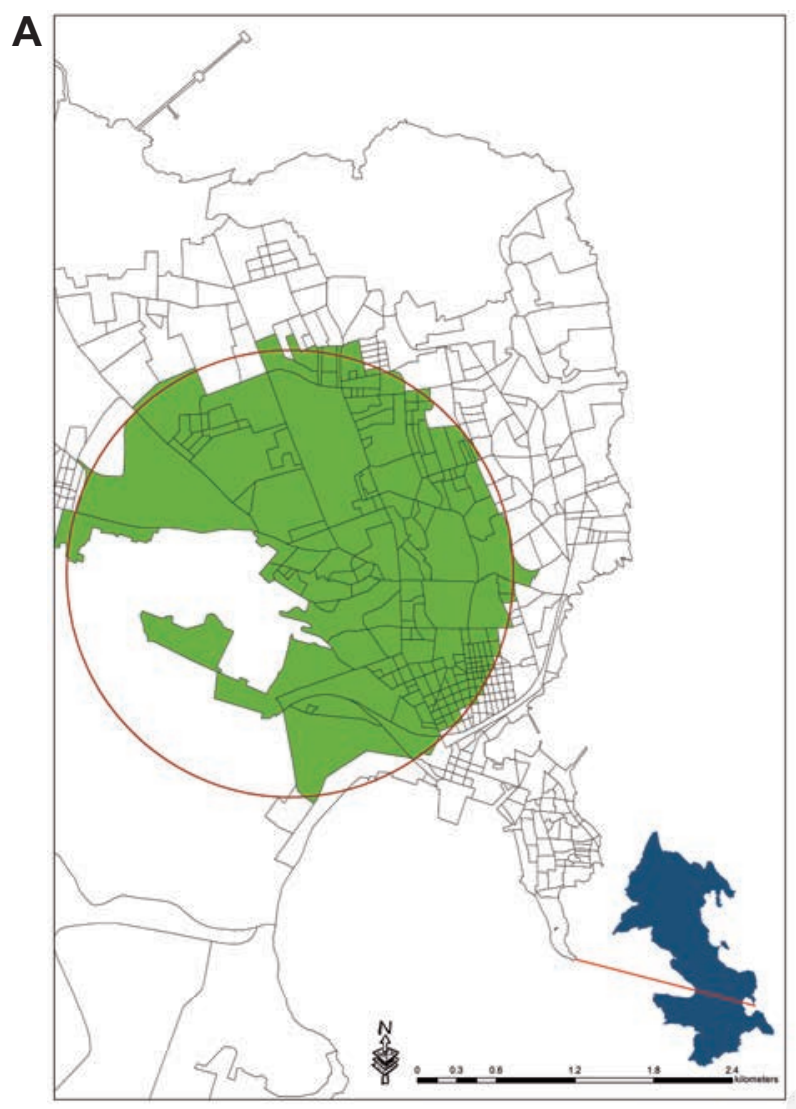

\begin{tabular}{|l|l|l|l|l|l|l|}
\hline Radilus $(\mathrm{km})$ & censuss-tracts number & Obs & Exp & RR & p.value \\
\hline 1.7 & 198 & 46 & 26.44 & 2.272 & 0.0627 \\
\hline
\end{tabular}

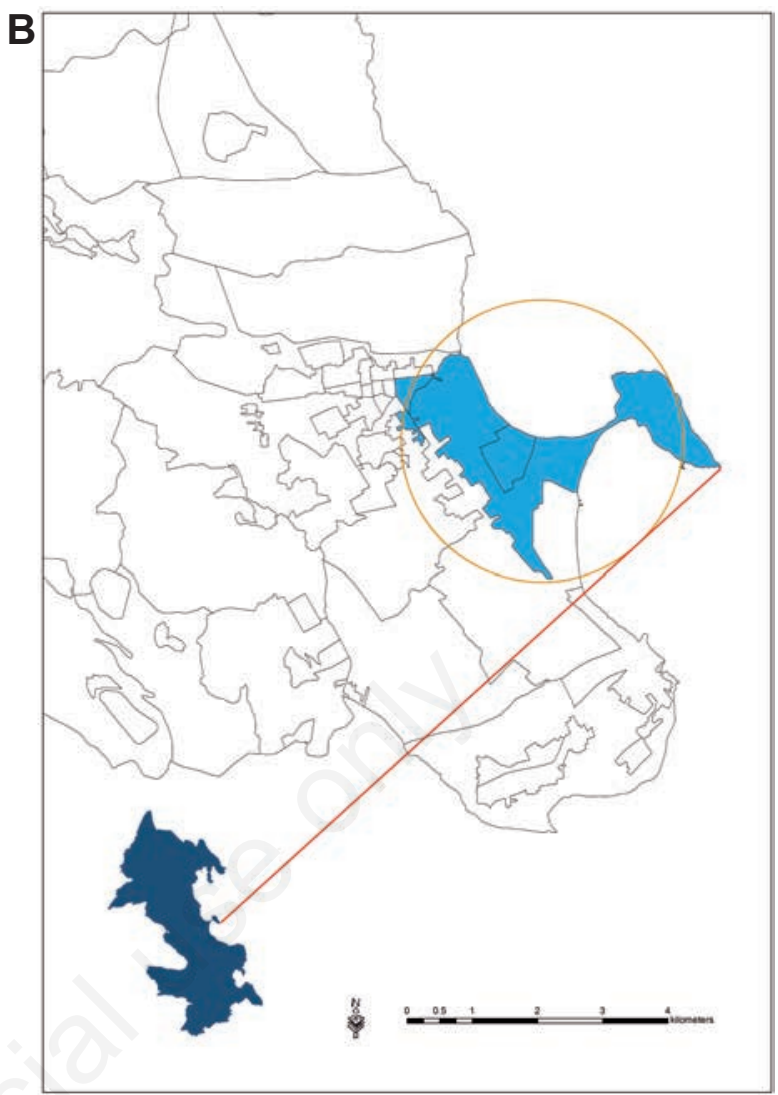

\begin{tabular}{|c|c|c|c|c|c|}
\hline Radius $(\mathrm{km})$ & census-tracts number & Obs & Exp & RR & p-value \\
\hline 2.16 & 4 & 3 & 0.13 & 45.782 & 0.0393 \\
\hline
\end{tabular}

Figure 5. Significant clusters of non-Hodgkin lymphoma in men including Syracuse (A) and of lymphocytic chronic leukaemia excluding Syracuse (B).

A

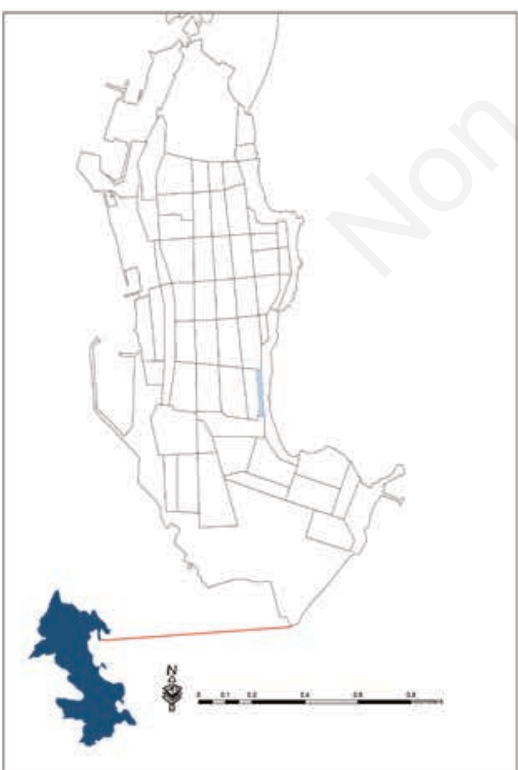

B

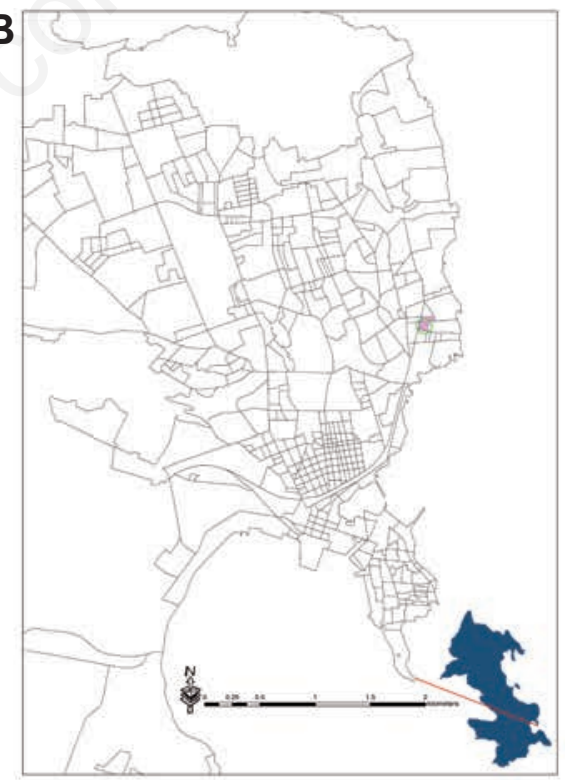

\begin{tabular}{|c|c|c|c|c|c|c|}
\hline Cluster & Radius (km) & census-tracts number & Obs & Exp & RR & p-value \\
\hline 1 & 0.07 & 2 & 4 & 0.17 & 24.006 & 0.037 \\
\hline 2 & 0 & 1 & 2 & 0.01 & 145.029 & 0.0847 \\
\hline
\end{tabular}
C

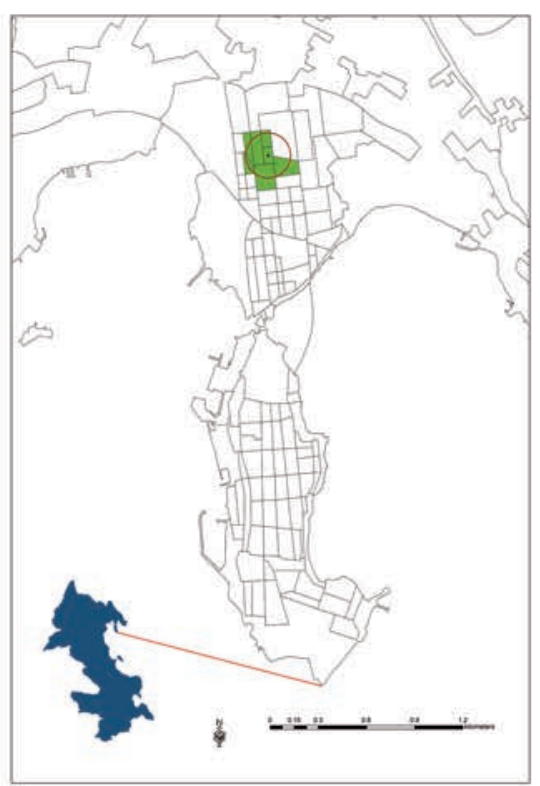

\begin{tabular}{|c|c|c|c|c|c|}
\hline Radius $(\mathrm{km})$ & census stracts number & Obs & Exp & RR & P-value \\
\hline 0.14 & 8 & 1.26 & 7.62 & 0.0137 \\
\hline
\end{tabular}

Figure 6. Significant clusters among women of pancreas cancer excluding Syracuse (A and B) and of thyroid cancer including Syracuse (C). 


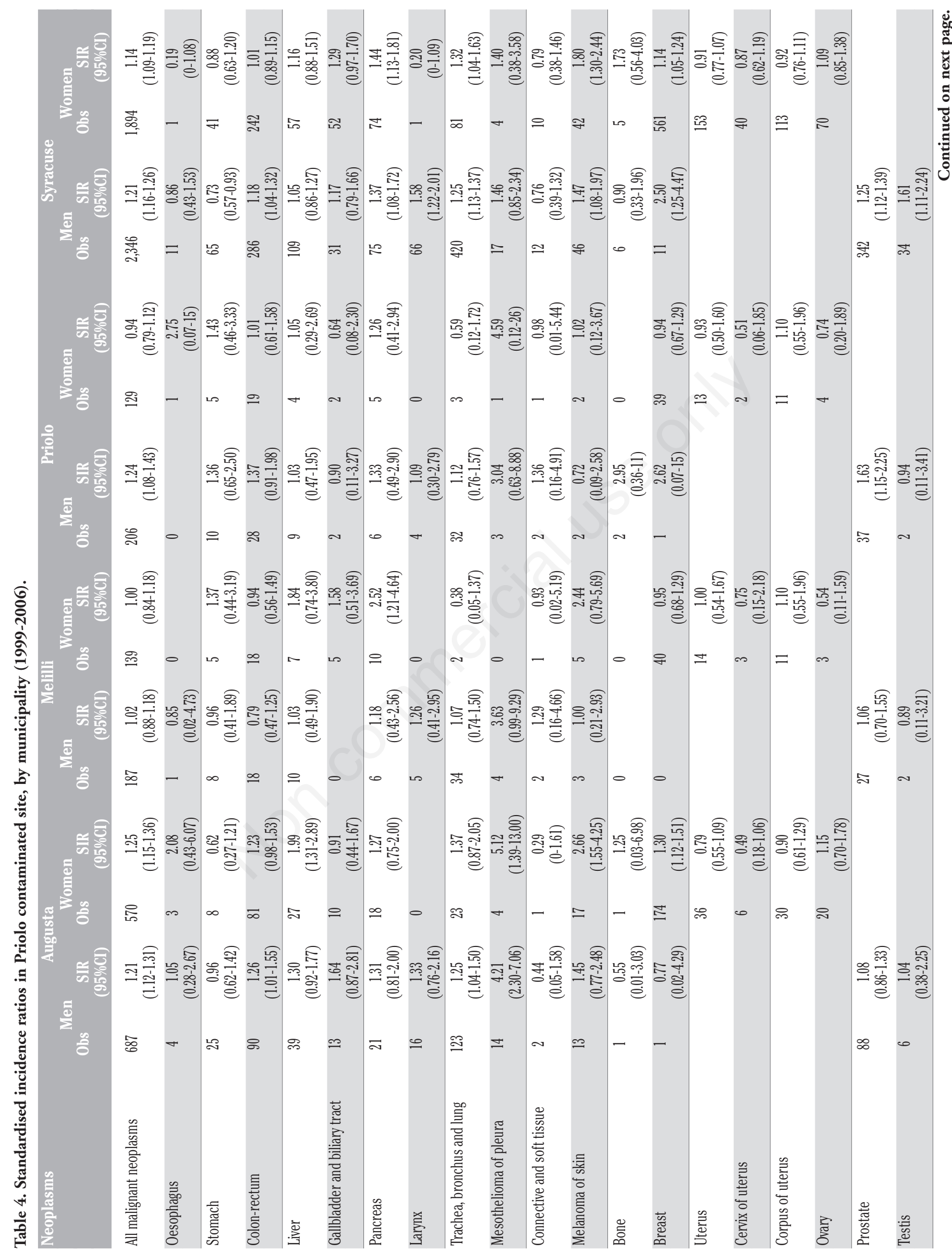




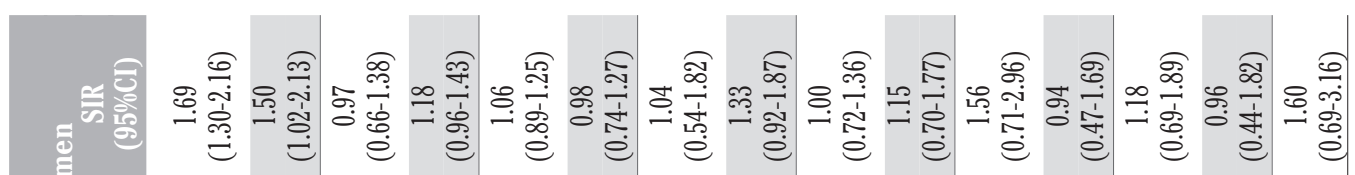

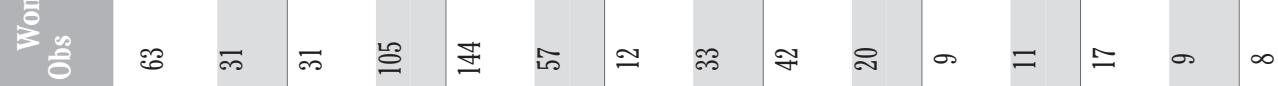
क 䍃

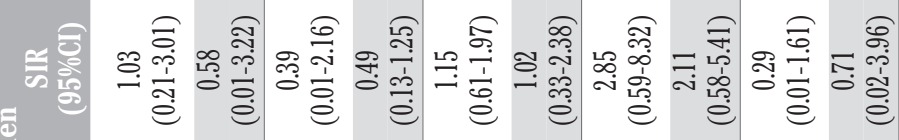

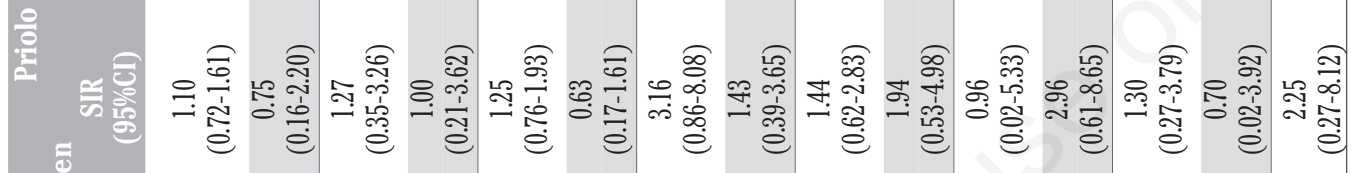
$\frac{5}{2}$

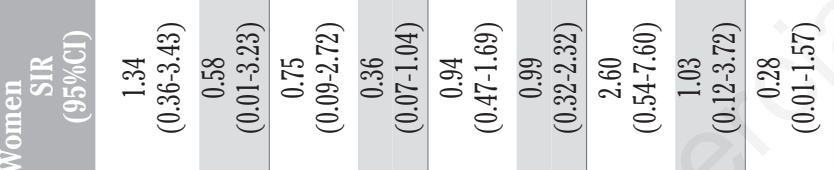

言

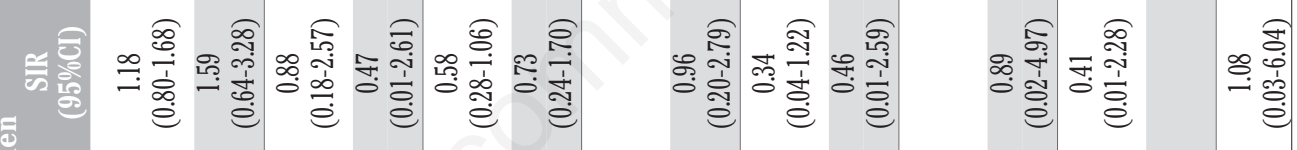

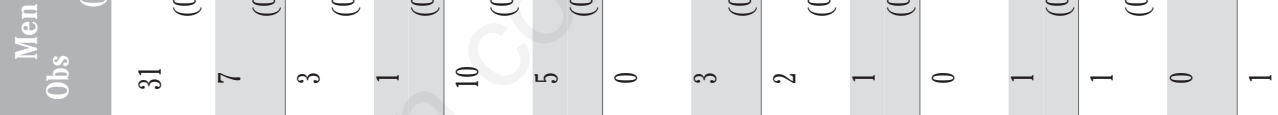

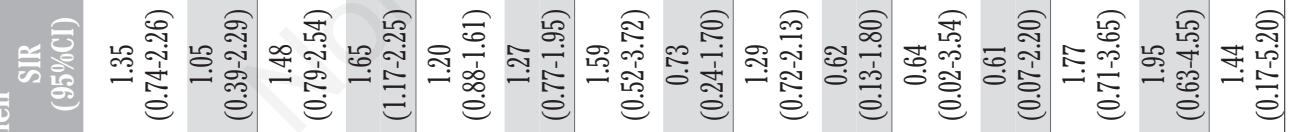

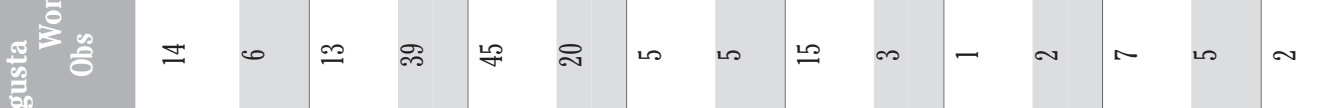

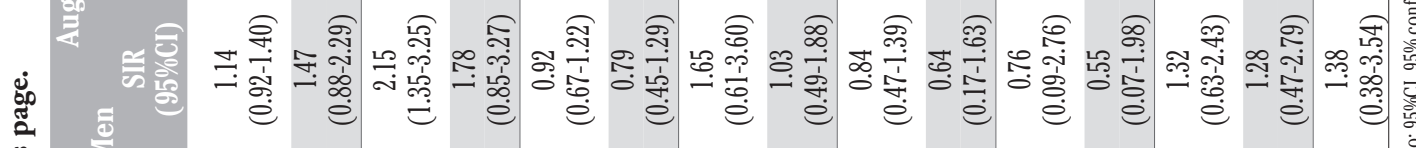

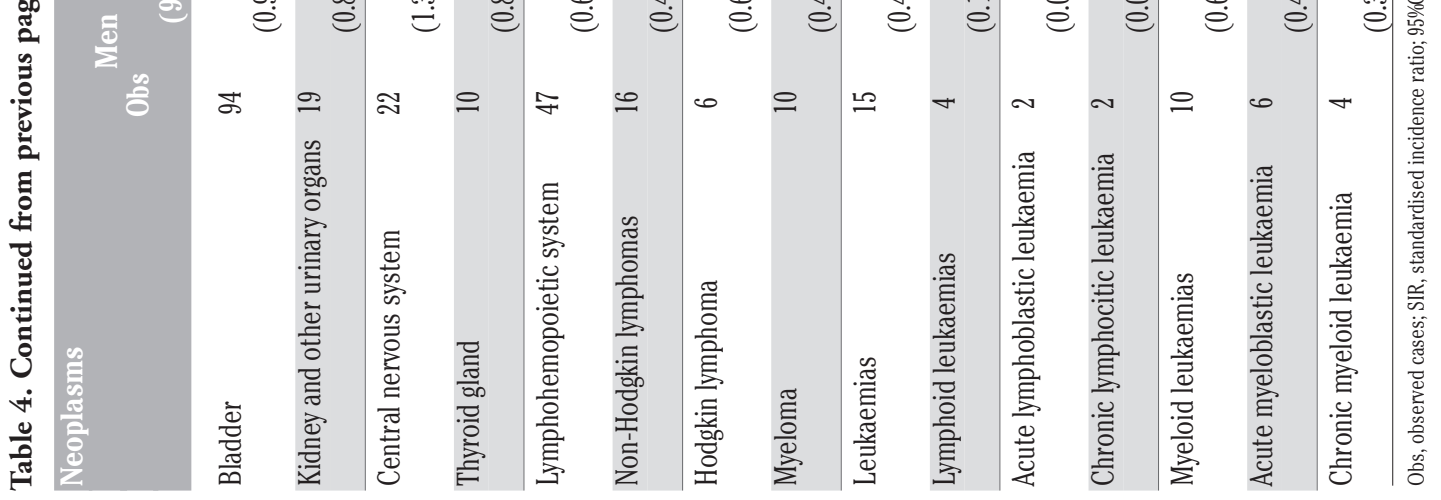


a large number of environmental chemicals are suspected of playing a role in breast cancer, in addition to hormone-related risk factors. Breast cancer is associated with sufficient evidence with exposure to alcoholic beverages, estrogen-progestogen therapies and diethylstilbestrol, $\mathrm{X}$ rays and gamma radiations (IARC, 2014a); limited evidence has been found for the association with digoxin, estrogen menopausal therapy, shift work that involves circadian disruption, tobacco smoking and exposure to ethylene oxide and PCBs (IARC, 2014a). The European case-control study on occupational exposure to endocrine disrupting chemicals in male breast cancer pointed out the increased incidence of male breast cancer with a possible role of occupational exposures to petrol and petroleum solvents in motor vehicle mechanics and, moreover, of occupational exposure to endocrine disrupting chemicals such as alkylphenolic compounds (Villeneuve et al., 2010). Cancers of the lung, bladder, breast, skin melanoma and pleural mesothelioma found in excess among both males and females deserve specific concern in view of $a$ priori evidence of association with exposure to PICs present in the area for the first four, and of the presence of potential asbestos sources for the latter.

Syracuse and, partially, Augusta municipality contributed to the findings concerning the CS overall area. The absence of observed excesses in Priolo and Melilli should not be overlooked, because of the low statistical power due to small population size. The results of clustering with the inclusion of Syracuse, detecting significant clusters of lung and non-Hodgkin lymphoma in a specific sub-area in this town, may be partly explained by different levels of air pollution exposure; the larger population size (with respect to the other municipalities of the CS) might have influenced the analysis. The lack of clustering at the census-tract level for some diseases found in excess at municipal level may be due to several factors: role of exposure pathways not related to spatial distribution of environmental contamination (e.g. drinking water, diet) and individual risk factors (occupational setting, socioeconomic status), and also to chance findings due to the low population size of each census-tract considered as the geographic unit in the cluster analysis. Nevertheless, some tumours (lung, thyroid, pancreas) produce clusters in populated sub-areas that seem to be affected by industrial air pollutants.

\section{Conclusions}

The present study contributes to the assessment of the spatial distribution of cancer diseases in the population living in the Priolo CS, Sicily. Etiological hypotheses on the links between the occurrence of a number of carcinogenic agents and the observed increased incidence of some cancer sites were generated. The results confirm a health status of the population living in Priolo CS that is worse than the Province of Syracuse taken as a whole, for which environmental exposure might play a role. Environmental remediation, currently in progress, should be accelerated together with an updating of the regulation of the industrial emissions. The establishment of an accurate environmental monitoring system integrated with a health surveillance plan is warranted.

\section{References}

ARPA Sicilia, 2008. Biomonitoraggio dell'area industriale siracusana. Qualità dell'aria mediante il bioaccumulo nei licheni. Indagine 2006-2007. ARPA Sicilia ed., Palermo, Italy.
Beccaloni E, Cicero MR, Falleni F, Piccardi A, Scaini F, Soggiu ME, Vanni F, Carere M, 2014. Environmental characterization and exposure evaluation. Epidemiol Prev 38(Suppl.1):137-43.

Cressie N, 2002. Statistics for spatial data. Chapman and Hall, London, UK.

Curado MP, Edwards B. Shin HR, Storm H, Ferlay J, Heanue M, Boyle P, 2007. Cancer incidence in five continents. International Agency for Research on Cancer, Lyon, France.

Dipartimento Attività Sanitarie ed Osservatorio Epidemiologico, Assessorato Regionale della Salute, 2012. Stato di salute della popolazione residente nelle aree a rischio ambientale e nei siti di interesse nazionale per le bonifiche. Rapporto 2012. Assessorato Regionale della Salute ed., Palermo, Italy.

ECHA, 2013. RAC concludes on nine scientific opinions for CLH. News ECHA/NA/13/43. Available from: http://echa.europa.eu/view-article//journal_content/title/rac-concludes-on-nine-scientific-opinionsfor-clh

IARC, 1993. IARC Monographs on the evaluation of carcinogenic risks to humans. Vol. 58. Beryllium, cadmium, mercury, and exposures in the glass manufacturing industry. International Agency for Research on Cancer, Lyon, France.

IARC, 1997. IARC Monographs on the evaluation of carcinogenic risks to humans. Vol. 69. Polychlorinated dibenzo-para-dioxins and polychlorinated dibenzofurans. International Agency for Research on Cancer, Lyon, France.

IARC, 1999. IARC Monographs on the evaluation of carcinogenic risks to humans. Vol. 71. Re-Evaluation of some organic chemicals, hydrazine and hydrogen peroxide. International Agency for Research on Cancer, Lyon, France.

IARC, 2001. IARC Monographs on the evaluation of carcinogenic risks to humans. Vol. 79. Some thyrotropic agents. International Agency for Research on Cancer, Lyon, France.

IARC, 2006a. IARC Monographs on the evaluation of carcinogenic risk to humans. Vol. 86. Cobalt in hard metals and cobalt sulfate gallium arsenide, indium phosphide and vanadium pentoxide. International Agency for Research on Cancer, Lyon, France.

IARC, 2006b. IARC Monographs on the evaluation of carcinogenic risk to humans. Vol. 87. Inorganic and organic lead compounds. International Agency for Research on Cancer, Lyon, France.

IARC, 2012a. IARC Monographs on the evaluation of carcinogenic risks to humans. Vol. 100C. A review of human carcinogens: arsenic, metals fibers and dusts. International Agency for Research on Cancer, Lyon, France.

IARC, 2012b. IARC Monographs on the evaluation of carcinogenic risk to humans. Vol. 100F. A review of human carcinogens: chemical agents and related occupations. International Agency for Research on Cancer, Lyon, France.

IARC, 2014a. IARC List of classifications by cancer sites with sufficient or limited evidence in humans. Volumes 1 to 113. International Agency for Research on Cancer, Lyon, France.

IARC, 2014b. IARC Monographs on the evaluation of carcinogenic risk to humans. Vol. 106. Trichloroethylene, tetrachloroethylene and some other chlorinated agents. International Agency for Research on Cancer, Lyon, France.

IARC, 2014c. IARC Monographs on the evaluation of carcinogenic risk to humans. Vol. 107. Polychlorinated biphenyls and polybrominated biphenyls. International Agency for Research on Cancer, Lyon, France.

Johnston K, Ver Hoef JM, Krivoruchko K, Lucas N, 2001. Using ArcGIS geostatistical analyst. ESRI, Redlands, USA.

Kuldorff M, 1997. A spatial scan statistic. Commun Stat 26:481-96.

Lakes Environmental, 2013. ISCST3 tech guide. Available from: 
http://www.weblakes.com/guides/iscst3/section1/index.html

Lauby-Secretan B, Loomis D, Grosse Y, El Ghissassi F, Bouvard V, Benbrahim-Tallaa L, Guha N, Baan R, Mattock H, Straif K, WHO International Agency for Research on Cancer, 2013. Carcinogenicity of polychlorinated biphenyls and polybrominated biphenyls. Lancet Oncol 14:287-8.

Madeddu A, Contrino ML, Tisano F, Sciacca S, 2009. I tumori in provincia di Siracusa dal 2002 al 2005: incidenza, mortalità, sopravvivenza, trend. Dipartimento di Igiene e Registro Tumori Integrato MeCt-Sr, Università degli Studi di Catania ed., Catania, Italy.

NTP, 2014. Report on carcinogens. US Department of Health and Human Services, Public Health Service, National Toxicology Program ed., Research Triangle Park, NC, USA. Available from: http://ntp.niehs.nih.gov/pubhealth/roc/roc13/

Pirastu R, Comba P, Conti S, Iavarone I, Fazzo L, Pasetto R, Zona A, Crocetti E, Ricci P, 2014. SENTIERI. Epidemiological study of residents in National Priority Contaminated sites: mortality, cancer incidence and hospital discharges. Epidemiol Prev 39(Suppl.1):1170.

Pirastu R, Pasetto R, Zona A, Ancona C, Iavarone I, Martuzzi M, Comba $\mathrm{P}, 2013$. The health profile of populations living in contaminated sites: SENTIERI approach. J Environ Public Health 2013:939267.

StataCorp, 2010. Stata: release 10. Statistical software. StataCorp LP, College Station, TX, USA.

USEPA, 1991. Integrated risk information system (IRIS) on vinyl chloride (CAS RN 75-01-4). United States Environmental Protection Agency ed., Cincinnati OH, USA.

USEPA, 1998. Integrated risk information system (IRIS) on chromium (VI) (CASR N 18540-29-9). United States Environmental Protection Agency ed., Cincinnati OH, USA.

USEPA, 2010. Integrated risk information system (IRIS). Toxicological review of inorganic arsenic (cancer) (2010 external review draft). United States Environmental Protection Agency ed., Cincinnati OH, USA. Available from: http://cfpub.epa.gov/ncea/iris_drafts/ recordisplay.cfm?deid $=219111$

USEPA, 2011. Toxicological review of trichloroethylene. United States Environmental Protection Agency ed., Cincinnati OH, USA.

USEPA, 2013. Toxicological (CASRN 50-32-8) review of benzo[a]pyrene in support of summary information on the integrated risk information system (IRIS). Available from: ofmpub.epa.gov/eims/eimscomm.getfile?p_download_id=520493

van Liedekerke M, Prokop G, Rabl-Berger S, Kibblewhite M, Louwagie G, 2014. Progress in the management of contaminated sites in Europe. Reference report by the Joint Research Centre of the European Commission. Publications Office of the European Union, Luxembourg.

Vicedo-Cabrera AM, Biggeri A, Grisotto L, Barbone F, Catelan D, 2013. A Bayesian kriging model for estimating residential exposure to air pollution of children living in a high-risk area in Italy. Geospat Health 8:87-95.

Villeneuve S, Cyr D, Lynge E, Orsi L, Sabroe S, Merletti F, Gorini G, Morales-Suarez-Varela M, Ahrens W, Baumgardt-Elms C, Kaerlev L, Eriksson M, Hardell L, Févotte J, Guénel P, 2010. Occupation and occupational exposure to endocrine disrupting chemicals in male breast cancer: a case-control study in Europe. Occup Environ Med 67:837-44.

World Health Organization, 2013. Contaminated sites and health. World Health Organization, Geneva, Switzerland.

Zona A, Marcello I, Carere M, Soggiu ME, Falleni F, Beccaloni E, Comba P, 2014. Index contaminants and target organs. Epidemiol Prev 38(Suppl.1):144-52. 